\title{
AGE OF DIAGNOSIS AND BODY MASS INDEX IN BREAST CANCER PATIENTS: ANALYSIS OF A BRAZILIAN REFERENCE CENTRE
}

Luiz Henrique Gebrim¹, André Mattar, Jorge Y. Shida', Roberto Hegg', Ana Luiza A. Faria', Felipe A. Cavagna 'Women's Reference Center, Hospital Pérola Byington - São Paulo (SP), Brazil.

Objetives: Breast cancer affects about 59,000 Brazilian women annually according to data from INCA 2018 (National Cancer Institute) and 14,388 deaths are related to the disease. There are few data about the age specific incidence in our Country and almost anything about the prevalence of obesity in our population. Pérola Byington Hospital is one of the most important cancer centers specialized breast cancer treatment in Brazil and we are responsible for treating about a thousand new cases of breast cancer annually. Methodology: We have created a web-based system that helped us to input information about the breast cancer cases treated in our hospital. This study was performed at the Pérola Byington Hospital evaluating the age of diagnosis and their body mass index (BMI) before the treatment. Descriptive data is shown. Results: There were 8,420 cases of breast cancer enrolled in our analysis and most of our cases were diagnosed with 50 or more years old ( $\mathrm{n}=5.507)$ which corresponds to $65.41 \%$. The patients' age ranged from 18 to 93 years, with a median of 54 years. Only $1.23 \%$ of the cases were diagnosed below 29 years of age and $33.2 \%$ of the cases were between 30 and 49 years. There was a considerably number of cases that have been diagnosed between 40 and 49 years old $(n=2.044)$ which correspond to $24.28 \%$ of our population. We made an analysis to see if from 2011 to 2017 there was any difference in incidence specified by age and it was not statistic significant. Regarding the BMI we were able to recover 5,878 cases of breast cancer and the majority of our patients were obese or overweigh by the time of diagnosis (65.8\%). Conclusions: In our analysis we have found that there are a lot of breast cancer in young patients and we have to take that in account to treat better our patients, there is no increase during the last years of young patients in our data. Most of our patients are obese or overweight at the time of diagnosis of breast cancer. 